\title{
Antimicrobial and Antioxidant Properties of Secondary Metabolites from White Rose Flower
}

\author{
Seong Soo Joo ${ }^{1 *}$, Yun-Bae Kim ${ }^{1}$ and Do Ik Lee ${ }^{2}$ \\ ${ }^{1}$ Research Institute of Veterinary Medicine, Chungbuk National University, Chungbuk 361-763, Korea \\ ${ }^{2}$ Department of Immunology, Chung-Ang University, Seoul 156-756, Korea \\ (Received on October 12, 2009; Accepted on December 31, 2009)
}

\begin{abstract}
Low-molecular-weight secondary metabolites from plants play an important role in reproductive processes and in the defense against environmental stresses or pathogens. In the present study, we isolated various volatiles and phenolic compounds from white Rosa rugosa flowers, and evaluated the pharmaceutical activities of these natural products in addition to their ability to increase survival in response to environmental stress and pathogen invasion. The DPPH and hydroxyl radical-mediated oxidation assay revealed that the white rose flower extract (WRFE) strongly scavenged free radicals in a dose dependent manner. Moreover, WRFE inhibited the growth of $E$. coli and fatally attacked those cells at higher concentration $(>0.5 \mathrm{mg} / \mathrm{mL})$. FITC-conjugated Annexin V stain provided further evidence that WRFE had strong antimicrobial activity, which may have resulted from a cooperative synergism between volatiles (e.g. 1-butanol, dodecyl acrylate and cyclododecane) and phenolic compounds (e.g. gallic acid) retained in WRFE. In conclusion, secondary metabolites from white rose flower hold promise as a potential natural source for antimicrobial and non-chemical based antioxidant agents.
\end{abstract}

Keywords : antimicrobial, antioxidant, genomic DNA, phenolic compounds, Rosa rugosa, volatiles

In a natural environment, plants can produce a very diverse range of low-molecular-weight natural products, also known as secondary metabolites. This diversity results, in part, from an evolutionary selection pressure for acquiring an improved defense against microbial or insect attacks (Dixon, 2001). These special metabolites constitute important active molecules, which differ widely in terms of structure and biological properties (Argolo et al., 2004). Plant secondary metabolism has multiple functions throughout the plant's life cycle. These functions can be classified as mediators in the interaction of the plant with its environment, such as plant-insect, plant-microorganism and plant-plant interactions

\footnotetext{
*Corresponding author.

Phone) +82-43-271-3246, FAX) +82-43-261-3246

E-mail) larryjoo@hanmail.net
}

(Harborne, 2001). The production of secondary metabolites forms part of the plant's defense system, for instance, the constitutive production of anti-feedants and phytoanticipins, and the inducible production of phytoalexins (Dixon, 2001). Evolutionary, floral scent is one of the adaptations that plants use to attract pollinators. The volatiles emitted from the flowers provide potential insect and animal pollinators with information about the location and identity in maximum pollen transfer to nonspecific flowers, increases fertilization rates and minimizes energy expenditure by the plants. Moreover, as a sessile organism, a plant cannot move to escape pathogen attack. Thus, plants have also evolved complex defense mechanisms to protect themselves against a vast array of pathogens (Dangl and Jones, 2001). In addition, low-molecular-weight natural products (e.g. ascorbic acid, glutathione, uric acid, tocopherol, carotinoids, polyphenols) have been shown to protect against reactive oxygen species (ROS) (Argolo et al., 2004; Vranová et al., 2002). Although these products, which accumulate in plants that have been subjected to stresses including various elicitors or signal molecules, have a variety of functions in plants, it is likely that they may provide unique resources for pharmaceuticals and may possess beneficial medicinal properties in humans (Zhao et al., 2005). Thus, these small molecules, which are pathologically very important to plant survival, can be applicable to our diet and have been shown to play a possible role in the prevention several chronic diseases (Hotta et al., 2002). In the present study, we aimed to demonstrate if the volatiles and phenolic compounds retained in white rose flower extract (WRFE) have pharmaceutically active antimicrobial and antioxidant properties other than that we have used as an ingredient in tea, a source of rose oil and for producing jams.

\section{Materials and Methods}

Plant Material and Chemicals. White rose flowers (Rosa rugosa) were freshly collected at Jincheon, Chungbuk in 2006, dried and ground in a rotor speed mill (Laval Lab Inc., QC, Canada). Pulverized flowers were sterilized using a $70 \%$ ethanol spray, followed by drying at $80^{\circ} \mathrm{C}$ for $24 \mathrm{~h}$, 
and the dried flowers were stored at $4^{\circ} \mathrm{C}$ by dissolving in dimethyl sulfoxidebe (DMSO) before use. Ascorbic acid, dimethyl sulfoxide (DMSO), hydroperoxide $\left(\mathrm{H}_{2} \mathrm{O}_{2}\right), 2$,2diphenyl-1-picrylhydrazyl hydrate (DPPH), bovine serum albumin (BSA), standard gallic acid, and ascorbic acid were purchased from Sigma (St. Louis, MO, USA).

Determination of total gallic acids. Total amount of gallic acids in WRFE was determined and expressed as milligrams of gallic acid equivalents per gram of fraction (Hsieh et al., 2008) with some modifications using a 96-well microplate reader. In brief, $10 \mu \mathrm{l}(200 \mu \mathrm{g} / \mathrm{mL})$ of WRFE was transferred into a 96-well microplate containing $160 \mu \mathrm{l}$ of distilled water, and $10 \mu \mathrm{l}$ of $1 \mathrm{~N}$ Folin-Ciocalteu's phenol reagent (Sigma). $20 \mu \mathrm{l}$ of $20 \%$ aqueous sodium carbonate solution was then added. The mixture was allowed to stand at ambient temperature for $20 \mathrm{~min}$. Absorbance of the developed dark blue-purple color was measured using a spectrophotometer at $735 \mathrm{~nm}$ (Spectra Max 340, Molecular Devices, CA, USA). The total amount of gallic aicd in WRFE was calculated using a calibration curve established with a gallic standard solution that ranged from 62.5 to $1000 \mathrm{mg} / \mathrm{ml}$.

GC-MS analysis. The volatile compounds of the hexane fraction of WRFE were determined using an Agilent 6890 gas chromatograph/5973N mass selective detector (Palo Alto, CA, USA), and separated on a HP-FFAP capillary column ( $30 \mathrm{~m}$ length $\times 0.25 \mathrm{~mm}$ i.d., $0.25 \mu \mathrm{m}$ film thickness). Helium was used as the carrier gas at a constant flow rate of $1 \mathrm{~mL} / \mathrm{min}$, and the oven temperature was set at $50^{\circ} \mathrm{C}$ for 5 min, raised to $230^{\circ} \mathrm{C}$ at $4^{\circ} \mathrm{C} / \mathrm{min}$, and held for $20 \mathrm{~min}$. The detector and injector temperatures were maintained at $250^{\circ} \mathrm{C}$. The ionizing energy of the mass selective detector was set at $70 \mathrm{eV}$, with a scanning mass range of $m / z$ 35-500. Most peaks were identified using the computer library (Wiley $275 \mathrm{~L}$ program). The homogeneity of the chromatographic peaks was checked with the aid of mass chromatograms for the characteristic fragment ions.

High performance liquid chromatography analysis. The hexane fraction of WRFE was analyzed by high performance liquid chromatography (HPLC) using a YounglinACME 9000 system (Younglin, Anyang, South Korea) with an YL9160 PDA detector. Spectral data were recorded from 190 to $900 \mathrm{~nm}$ during the whole run. For separation, a Mightysil RP-18 GP column $(4.6 \times 250 \mathrm{~mm}, 5 \mu \mathrm{m}$, Kanto Chemical, Japan) was used, and the solvent flow rate was held constant at $0.6 \mathrm{~mL} / \mathrm{min}$. The mobile phase used for separation consisted of solvent A (acetonitrile) and solvent $\mathrm{B}(10 \mathrm{mM}$ phosphoric acid, $\mathrm{pH} 2.5)$. The following gradient elution procedure was used: $0 \mathrm{~min} 10 \% \mathrm{~A}, 0-10 \mathrm{~min} 5 \%$
A, $10-40 \min 50 \%$ A, $40-41 \min 100 \%$ A, 41-51 $\min 100 \%$ A, 51-61 min $10 \% \mathrm{~A}$. The injection volume was $20 \mu \mathrm{l}$ for analysis and the gallic acid standard was prepared in HPLCgrade methanol. Concentration of gallic acid was determined from standard curves prepared by injecting different concentrations of gallic acid standards. The gallic acid was identified and quantified by comparing their retention time and UV-visible spectral data to known previously injected standards.

Measurement of DPPH radical scavenging activity. The DPPH radical is one of the few stable organic nitrogen radicals, which bears a deep-purple color. To evaluate the free radical scavenging activity, WRFE were allowed to react with the DPPH solution. In brief, WRFE powder was dissolved in DMSO as a stock solution $(100 \mathrm{mg} / \mathrm{mL})$ and reacted with $0.3 \mathrm{mM}$ DPPH in methanol. Various concentrations of WRFE (1 to $32 \mu \mathrm{g} / \mathrm{mL}$ ) were reacted with the DPPH radical solution for $20 \mathrm{~min}$ at room temperature. The absorbance was then measured at $517 \mathrm{~nm}$, and the DPPH free radical scavenging activity was calculated using the following equation: DPPH scavenging activity $(\%)=[\mathrm{Ac}-$ (A-(As) ]/Ac $\times 100$ (1), where Ac is the absorbance of the control DPPH solution, A is the absorbance of the sample with the DPPH solution, and As is the absorbance of the sample.

Hydroxyl radical-mediated oxidation assay. Hydroxyl radical-mediated oxidation experiments were performed using a metal-catalysed reaction as described previously (Mayo et al., 2003), with some modifications. The target protein, BSA, was dissolved in a $150 \mathrm{mM}$ phosphate buffer $(\mathrm{pH} 7.3$ ) at a final concentration of $0.5 \mathrm{mg} / \mathrm{mL}$. The BSA solution was incubated with and without $100 \mu \mathrm{M}$ copper $\left(\mathrm{Cu}^{2+}\right)$ and $2.5 \mathrm{mM} \mathrm{H}_{2} \mathrm{O}_{2}$ in the presence and absence of WRFE. The control antioxidant was $50 \mu \mathrm{M}$ of ascorbate, which was directly dissolved in PBS. The reactions were carried out in open tubes and placed in a shaking water bath that was maintained at $37^{\circ} \mathrm{C}$. After the reaction was completed, each mixture was separated on a $10 \%$ sodium dodecyl sulfate polyacrylamide gel electrophoresis (SDS-PAGE), and stained with $0.1 \%$ Coomassie blue solution.

Growth inhibition and DNA assay in Escherichia coli strain BL21 (DE3). Cell growth was measured using a spectrophotometer at $620 \mathrm{~nm}$ (Spectra Max 340, Molecular Devices, CA, USA) at $1 \mathrm{~h}, 2 \mathrm{~h}$, and $3 \mathrm{~h}$ culture after treatment with essential oil from Chamaecypris obtuse (0.01 and $0.1 \%)$, gallic acid (10 and $100 \mu \mathrm{g} / \mathrm{mL})$ and WRFE (0.1, 0.5 and $1 \mathrm{mg} / \mathrm{mL}$ ) in 96-well plate. Essential oil and gallic acid were used as a positive control for volatiles and phenolic compounds, respectively. For the gene assay, 
BL21 cells were transformed with the $p c \mathrm{DNA} 3.1^{+}$plasmid and grown in Luria-Bertani (LB) medium supplemented with $100 \mu \mathrm{g} \mathrm{mL} \mathrm{m}^{-1}$ ampicillin. After culture overnight, cells were diluted at a 1:100 ratio with fresh LB media and directly stressed with $1 \mathrm{mM} \mathrm{H} \mathrm{O}_{2}, 1 \%$ essential oil, various concentrations of WRFE ( 0.1 to $0.5 \mathrm{mg} / \mathrm{mL}$ ), and cultured for $4 \mathrm{~h}$ at $37^{\circ} \mathrm{C} / 250 \mathrm{rpm}$. Genomic DNA was isolated using a QIAamp ${ }^{\circledR}$ DNA Mini Kit (QIAGEN, Germany) and the plasmid DNA was purified from the same cell pellets using the QiAprep ${ }^{\circledR}$ Spin Miniprep Kit (QIAGEN, Germany).

Annexin V-FITC/Propidium iodide staining. For determining cell damage, E. coli $\mathrm{DH} 5 \alpha$ were treated with essential oil (1\%), gallic acid $(1 \mathrm{mg} / \mathrm{mL})$ and WRFE (1 mg/ $\mathrm{mL}$ ), and cultured for $4 \mathrm{~h}$ at $37^{\circ} \mathrm{C}$ in the LB media. $1 \mathrm{mM}$ $\mathrm{H}_{2} \mathrm{O}_{2}$ was used as a positive control. After the culture, cells were collected by centrifugation at $10,000 \mathrm{rpm}$ for $5 \mathrm{~min}$, cell pellets were washed with ice-cold phosphate buffered saline solution (PBS), resuspended in PBS, fixed with 4\% paraformaldehyde for $15 \mathrm{~min}$, and stained with Annexin VFITC and propidium iodide (1:2.5 ratio) for $2 \mathrm{~h}$ on ice in the dark. Dead or dying cells were determined using an Olympus IX71 inverted microscope (Olympus, Tokyo, Japan) and morphologic changes were compared by merging figures captured at the same sites.

Statistical analysis. The results obtained were expressed as mean \pm SD, and two-way ANOVA (SPSS 12.0 version) was used to statistically compare the groups. Results with $p$ value $<0.05$ were considered statistically significant.

\section{Results}

Determination of total phenolic compounds. Total amount of gallic acids was determined to elucidate the nature of the extract, which may indicate total phenoic compounds contained in WRFE. WRFE contained high amount of gallic acid (170.3 $\pm 18.1 \mathrm{mg}$ of gallic acid equival/g of dry weight), suggesting that WRFE may have a potent antioxidant activity.

GC-MS and HPLC analysis. In GC-MS analysis, we found that WRFE contained different volatile components and active phenolic compounds, which may have varying antioxidant and antimicrobial activities (Jang et al., 2008; Strobel et al., 2001). The major aroma constituents of WRFE were 1-butanol, dodecyl acrylate and cyclododecane, which constituted more than $60 \%$ of the total amount of volatiles (Fig. 1A). Moreover, higher amounts of gallic acid $(101.23 \mu \mathrm{g} / \mathrm{g})$ in WRFE were identified by HPLC (Fig. 1B). The presence of gallic acid was confirmed by UV spectrum of gallic acid in the hexane fraction and the
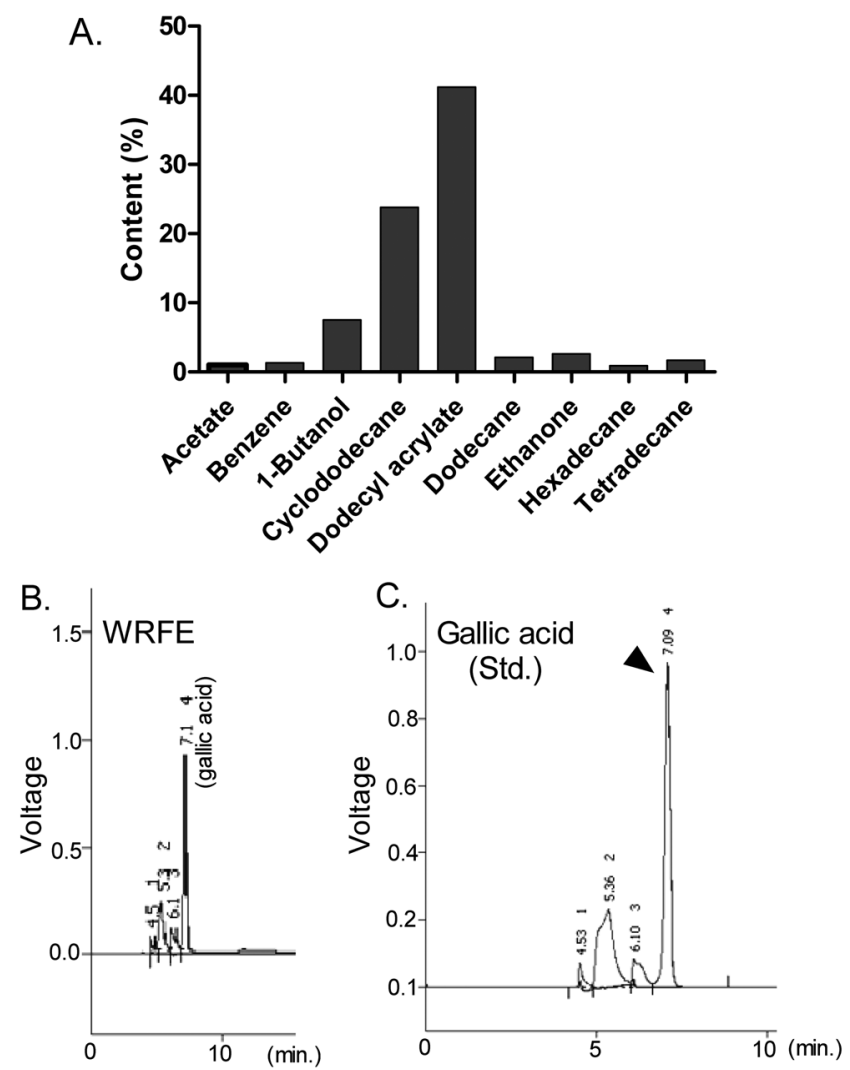

Fig. 1. Chromatogram analysis. (A) Various volatiles were determined in WRFE as described in Materials and methods, and are represented as (\%) contents. (B, C) Peak 4 indicates that gallic acid was present in WRFE at a high concentration. Gallic acid, a phenolic compound, in WRFE was identified and compared with the standard compound (arrowed).

standard compound (Fig. 1C).

DPPH radical scavenging and radical-mediated oxidation inhibition assay. DPPH is typically used as a reagent to evaluate the free radical scavenging activity of various antioxidant substances. Experimentally, DPPH is a stable free radical and accepts an electron or hydrogen radical to become a stable diamagnetic molecule. In the DPPH assay, WRFE plateued in $20 \mathrm{~min}$ at a concentration of $16 \mu \mathrm{g} / \mathrm{mL}$ ( $>80 \%$ scavenging), while ascorbic acid, an anti-oxidant control, did not plateau at the same concentration (Fig. 2A). This result strongly suggests that WRFE could be a powerful scavenger for free radicals and a potential substitute for ascorbic acid. To determine whether WRFE had proteinlevel radical scavenging properties, degradation of BSA by $\mathrm{Cu}^{2+}$ and $\mathrm{H}_{2} \mathrm{O}_{2}$ was monitored in the presence of 1 to $25 \mu \mathrm{g} /$ $\mathrm{mL}$ WRFE, as described in Materials and methods. As shown in Fig. 2B, WRFE successfully protected against the breakdown of BSA as did $0.5 \mathrm{mM}$ ascorbic acid by efficient inhibition of the degradation of BSA by free radicals at all tested concentrations. No noise effect from the vehicle 

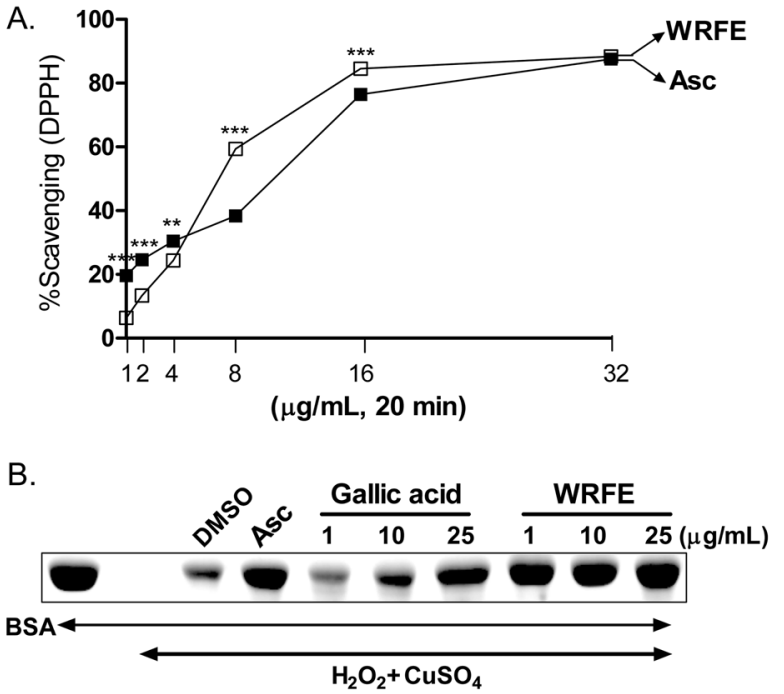

Fig. 2. Radical scavenging activity and PAGE profiles of the BSA protein with $\mathrm{Cu}^{2+} / \mathrm{H}_{2} \mathrm{O}_{2}$. (A) DPPH free radical scavenging activity of WRFE at different concentrations ( 1 to $32 \mu \mathrm{g} / \mathrm{mL}$ ) was determined over a fixed time (20 min.). Ascorbic acid (Asc) was used as an anti-oxidant control. (B) The gels show the protein obtained without treatment, with $\mathrm{Cu}^{2+} / \mathrm{H}_{2} \mathrm{O}_{2}$, and at different concentrations of WRFE ( 1 to $25 \mu \mathrm{g} / \mathrm{mL}$ ) and phenolic control, gallic acid (1 to $25 \mu \mathrm{g} / \mathrm{mL})$. Ascorbic acid $(0.5 \mathrm{mM})$ and $10 \%$ DMSO were used as positive and vehicle controls, respectively. The final steps include the incubation of all reactants, including BSA, for $2 \mathrm{~h}$ and electrophoresis in 10\% SDS-PAGE. Data are expressed as mean \pm SD. $* * \mathrm{P}<0.01, * * * \mathrm{P}<0.001$ between WRFE and Asc (ascorbic acid).

control (DMSO) was detected during the degradation of BSA.

Cell damage and growth inhibition assay. Bacterial cell growth was measured in the $E$. coli strain BL21 (DE3) at $620 \mathrm{~nm}$, and inhibition of bacterial cell growth was compared between the WRFE- and essential oil/gallic acidtreated group after a $3 \mathrm{hs}$ culture. At the indicated hours (1 $\mathrm{h}, 2 \mathrm{~h}$, and $3 \mathrm{~h}$ ) and concentrations, higher concentrations of WRFE $(0.5$ and $1 \mathrm{mg} / \mathrm{mL})$ inhibited bacterial cell growth, whereas higher concentrations of essential oil $(0.1 \%)$ and gallic acid $(0.1 \mathrm{mg} / \mathrm{mL})$ only minimally inhibited cell growth (Fig. 3A). This strongly suggests that WRFE, which contains both volatiles and phenolic compounds, may have effective antimicrobial activity at a higher concentration. Next $p c$ DNA3. $1^{+}$-transformed BL21 cells were treated with $\mathrm{H}_{2} \mathrm{O}_{2}(1 \mathrm{mM})$, essential oil (1\%), and WRFE ( 0.1 to $0.5 \mathrm{mg} /$ $\mathrm{mL}$ ) for $4 \mathrm{~h}$. Genomic and plasmid DNA from the same cell pellets were isolated and compared on an 1.2\% agarose gel. As shown in Fig. 3B, genomic and plasmid DNA was fully damaged when treated with $\mathrm{H}_{2} \mathrm{O}_{2}(1 \mathrm{mM})$ or essential oil $(1 \%)$, whereas genomic and plasmid DNA in WRFE-treated cells was damaged in a dose dependent manner, suggest-
A. Growth inhibition (E. coli)

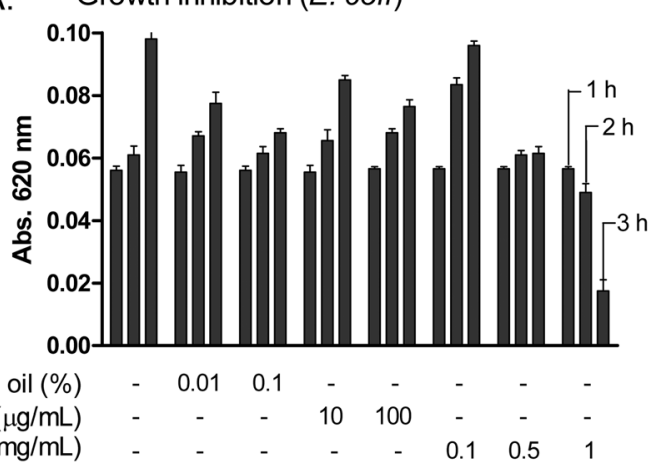

B.

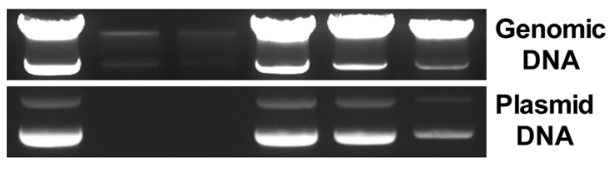

$\begin{array}{rrrrrll}\mathrm{H}_{2} \mathrm{O}_{2} & - & 1 \mathrm{mM} & - & - & - & - \\ \mathrm{EO} & - & - & 1 \% & - & - & - \\ \text { WRFE } & - & - & - & 0.1 & 0.25 & 0.5(\mathrm{mg} / \mathrm{mL})\end{array}$

Fig. 3. Growth inhibition analysis in E. coli. (A) Growth of $E$. coli was measured at $1 \mathrm{~h}, 2 \mathrm{~h}$, and $3 \mathrm{~h}$ culture after the treatment with essential oil (EO, 0.01 and $0.1 \%$ ), gallic acid (10 and $100 \mu \mathrm{g} / \mathrm{mL})$ and WRFE $(0.1,0.5$ and $1 \mathrm{mg} / \mathrm{mL})$ using a spectrophotometer at $620 \mathrm{~nm}$. (B) Both the genomic DNA and the plasmid DNA was isolated from the $p c$ DNA3.1 $1^{+}$-transformed BL21 strain after $4 \mathrm{~h}$ culture with $\mathrm{H}_{2} \mathrm{O}_{2}(1 \mathrm{mM})$, essential oil (EO, 1\%), and WRFE $(0.1$ to $0.5 \mathrm{mg} / \mathrm{mL})$. DNAs were electrophoresed on a $1.2 \%$ agaros gel and compared with $\mathrm{H}_{2} \mathrm{O}_{2}$ control. Data are expressed as mean \pm SD.

ing that the antimicrobial activity of WRFE may be from the activities of the volatiles.

Annexin V-FITC staining of dead or dying $E$. coli. Annexin $\mathrm{V}$ is a phospholipid binding protein, and this property makes Annexin $\mathrm{V}$ a powerful and selective tool for detect dying (apoptotic) cells. FITC-conjugated Annexin V was used to stain dead or dying cells and propidium iodide was used for counter-staining the same cells. As shown in Fig. 4, a 4 hs culture with essential oil and WRFE fatally attacked E. coli as much was observed in the $\mathrm{H}_{2} \mathrm{O}_{2}$-treated cells, suggesting that the bacteria-kills were induced by the volatiles retained in WRFE. However, it cannot be ruled out that gallic acid synergistically supported the antibacterial property of WRFE (Sikkema et al., 1995). These apoptotic features were coincident with the results of DNA damages shown in Fig. 3B.

\section{Discussion}

Plants produce an amazing diversity of low molecular weight organic compounds known as secondary or specialized 


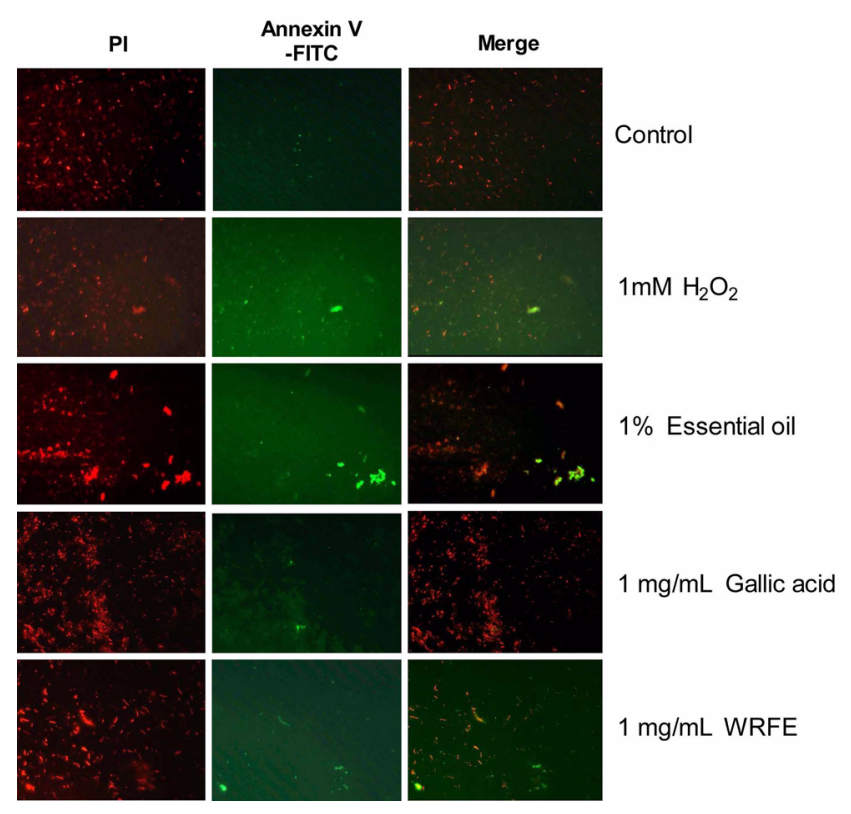

Fig. 4. Images of damaged cells. E. coli DH5 $\alpha$ cells were treated with essential oil (1\%), gallic acid $(1 \mathrm{mg} / \mathrm{mL})$, and WRFE (1 mg/ $\mathrm{mL}$ ), and cultured for $4 \mathrm{~h}$ at $37^{\circ} \mathrm{C}$ in the LB media. Annexin VFITC and Propidium iodide (PI) were added as described in Materials and methods. Annexin V-FITC-stained cells (dark blue) represent dead or dying cells, and PI (dark red) was used as a counterstain. Magnification, $\times 200$.

metabolites (Pichersky, 2000). More than 1\% of these metabolites are lipophilic molecules with low boiling points and high vapor pressures at ambient temperature. They are mainly represented by terpenoids, phenylpropanoids/benzenoids, fatty acid derivatives and amino acid derivatives. These volatile compounds are released from leaves flowers, and fruits into the atmosphere and from roots into the soil. The primary functions of airborne volatiles are to defend plants against herbivores and pathogens, to attract pollinators, seed dispensers, and other beneficial animals and microorganisms, and to serve as signals in plant-plant interaction (Dudareva, 2008). Many floral volatiles have anti-microbial or anti-herbivore activity (De Moraes, 2001; Hammer et al., 2003), and so could also act to protect valuable reproductive parts of plants from enemies. Volatile emission in flowers and accumulation in leaves and fruits follow similar developmental patterns, increasing during the early stages of organ development (Dudareva and Pichersky, 2000). The induction of direct and indirect plant defenses in response to herbivore and other biotic stresses is well established (Karban et al., 2000). It has long been recognized that some volatiles have antimicrobial properties (Nychas, 1995). Besides antibacterial properties, they also have been shown to exhibit antiviral and antimycotic properties (Bishop, 1995; Mari et al., 2003). In addition to this anti-microbial activity, anti-oxidant activity is another main characteristic of plant secondary metabolites, mainly from phenolic compounds (Sanchez-Moreno, 1999).

In GC-MS analysis, we found that WRFE contained various volatiles including 1-butanol, dodecyl acrylate and cyclododecane, which constituted more than $60 \%$ of the total amount of volatiles. Among these major volatiles, 1butanol is believed to act as the most active compound in effectively killing bacteria (Strobel, 2001). In addition, higher amounts of gallic acid in WRFE, which may take part in preventing stresses against various elicitors or signal molecules for the plant survival, significantly scavenged free radicals both in the DPPH and hydroxyl radical-mediated oxidation assay, exceeding the activities of ascorbic acid at the same concentrations. This suggests that WRFE may have highly creditable potential use as both an antimicrobial and antioxidant agent. Although the antimicrobial properties of volatiles have been demonstrated in many reports, the mechanisms of action have not been clearly defined in detail. One thing that we can assume about the mode of antibacterial action is that it is not attributable to one specific mechanism but rather there are several targets in the cell (Carson et al., 2002). An important characteristic of volatiles is their hydrophobicity, which enables them to partition with the lipids of the bacterial cell membrane and mitochondria, disturbing the structures and rendering them more permeable (Sikkema et al., 1994). Thus, the internal cellular content of the cell, including critical molecules and ions, will leak out ultimately leading to bacterial cell death (Denyer and Hugo, 1991). In addition, the high amount of phenolic compounds in the extract may also lead to the disturbance of the cytoplasmic membrane, disrupting the proton motive force, elelctron flow, active transport and coagulation of cell contents (Sikkerma et al., 1995; Davidson, 1997). These mechanistic features were confirmed from the degradation of genomic and plasmid DNA of $p c$ DNA3.1 $1^{+}$ transformed BL21 strain. These assays revealed that treatment with higher amounts of WRFE degraded both DNAs. Further evidence of this effect was demonstrated by staining the cells treated with WRFE $(1 \mathrm{mg} / \mathrm{mL})$ with the FITCconjugated Annexin V stain (dark blue). Interestingly, WRFE was more effective than the volatiles and phenolic controls. This strongly suggests that the volatiles and phenolic compounds retained in WRFE synergistically acted on the bacteria to induce fatal cell death. In conclusion, WRFE, which contains highly effective volatiles and phenolic compounds, may exhibit strong antibacterial activity against environmental or food borne pathogens and, therefore, secondary metabolites from white rose flower hold promise as a natural source for antimicrobial and nonchemical based antioxidant agents. 


\section{Acknowledgement}

This study was supported by a grant of the Korea Healthcare technology R\&D Project, Ministry for Health, Welfare \& Family Affairs, Republic of Korea (A091121).

\section{References}

Argolo, A. C. C., Sant'Ana, A. E. G., Pletsch, M. and Coelho, L. C. B. B. 2004. Antioxidant activity of leaf extracts from Bauhinia monandra. Bioresour. Technol. 95:229-233.

Bishop, C. D. 1995. Antiviral activity of the essential oil of Melaleuca alternifolia (Maiden and Betche) Cheel (tea oil) against tobacco mosaic virus. J. Essent. Oil. Res. 7:641-644.

Carson, C. F., Mee, B. J. and Riley, T. V. 2002. Mechanism of action of Melaleuca laternifolia (tea tree) oil on staphylococcus aureus determained by time-kill, lysis, leakage and salt tolerance assays and electron microscopy. Antimicrob. Agents Chemother. 46:1914-1920.

Dangl, J. L. and Jones, J. D. 2001. Plant pathogens and integrated defence responses to infection. Nature 411:826-833.

Davidson, P. M. 1997. Chemical preservatives and natural antimicrobial compounds. In: Food microbiology fundamentals and frontiers, ed. by M. P. Doyle, L. R. Beuchat and T. J. Montville, pp. 520-556. American Society for Microbiology Press, Washington (DC).

De Moraes, C. M., Mescheer, M. C. and Tumlison, J. H. 2001. Caterpillar-induced nocturnal plant volatiles repel nonspecific females. Nature 410:577-580.

Denyer, S. P. and Hugo, W. B. 1991. Biocide-induced damage to the bacterial cytoplasmic membrane. In: Mechanisms of action of chemical Biocides: The Society for Applied Bacteriology, Technical Series No 27, ed. by S. P. Denyer and W. B. Hugo, pp. 171-188. Oxford Blackwell Scientific Publication, Oxford.

Dixon, R. A. 2001. Natural products and plant disease resistance. Nature 411:843-847.

Dudareva, N. and Pichersky, E. 2000. Biochemistry and molecular genetic aspects of floral scents. Plant. Physiol. 122:627633.

Dudareva, N. and Pichersky, E. 2008. Metabolic engineering of plant volatiles. Curr. Opin. Biotechnol. 19:181-189.

Hammer, K. A., Carson, C. F. and Riley, T. V. 2003. Antifungal activity of the components of Melaleuca alternifolia (tea tree) oil. J. Appl. Microbiol. 95:853-860.

Harborne, J. B. 2001. Twenty-five years of ecology. Nat. Prod. Rep. 18:361-379.

Hotta, H., Nagano, S., Ueda, M., Tsujino, Y., Koyama, J. and Osa- kai, T. 2002. Higher radical scavenging activities of polyphenolic antioxidants can be ascribed to chemical reactions following their oxidation. Biochim. Biophys. Acta 1572:123132.

Hsieh, M.-C., Shen, Y.-J., Kuo, Y.-H. and Hwang, L. S. 2008. Antioxidative activity and active components of Longan (Dimocarpus longan Lour.) flower extracts. J. Agric. Food Chem. 56:7010-7016.

Jang, H.-W., Ka, M.-H. and Lee, K.-G. 2008. Antioxidant activity and characterization of volatile extracts of Capsicum annuum L. and Allium spp. Flavour. Fragr. J. 23:178-184.

Karban, R., Baldwin, I. T., Baxter, K. J., Laue, G. and Felton, G. W. 2000. Communication between plants: induced resistance in wild tobacco plants following clipping of neighboring sagebrush. Oecologia 125:66-71.

Mari, M., Bertolini, P. and Pratella, G. C. 2003. Non-conventional methods for the control of post-harvest pear diseases. J. Appl. Microbiol. 94:761-766.

Mayo, J. C., Tan, D. X., Sainz, R. M., Natarajan, M., LopezBurillo, S. and Reiter, R. J. 2003. Protection against oxidative protein damage induced by metal-catalyzed reaction or alkylperoxyl radicals: comparative effects of melatonin and other antioxidants. Biochim. Biophys. Acta. 1620:139-150.

Nychas, G. J. E. 1995. Natural antimicrobials from plants. In: New Methods of Food Preservation, ed. by G. W. Gould, pp. 58-89. Blackie Academic and professional, Glasgow.

Pichersky, E. and Gang, D. R. 2000. Genetics and biochemistry of secondary metabolites in plants: an evolutionary perspective. Trends Plant Sci. 5:439-445.

Sanchez-Moreno, C., Larrauri, J. A. and Saura-Calixto, F. 1999. Free radical scavenging capacity an inhibition of lipid oxidation of wines, grape juices and related polyphenolic constituents. Food Res. Int. 32:407-412.

Sikkema, J., De Bont, J. A. M. and Poolman, B. 1994. Interactions of cyclic hydrocarbons with biological membranes. J. Biol. Chem. 269:8022-8028.

Sikkema, J., De Bont, J. A. M. and Poolman, B. 1995. Mechanisms of membrane toxicity of hydrocarbons. Microbiol. Rev. 59:201-222.

Strobel, G. A., Dirkse, E., Sears, J. and Markworth, C. 2001. Volatile antimicrobials from Muscodor albus, a novel endophytic fungus. Microbiology 147:2943-2950.

Vranová, E., Inzé, D. and Van Breusegem, F. 2002. Signal transduction during oxidative stress. J. Exp. Bot. 53:1227-1236.

Zhao, J., Davis, L. C. and Verpoorte, R. 2005. Elicitor signal transduction leading to production of plant secondary metabolites. Biotechnol. Adv. 23:283-333. 